16 Weitgasser $\mathrm{H}$. The use of pentoxifylline "Trental 400 , in the treatment of leg ulcers: results of a double-blind trial. P'harmatherapeutica 1983;3 suppl $1: 1+3-51$.

17 Anonymous. Dressings for leg ulcers. Drug Ther Bull 1986;24:9-12.

18 Blair SD, Wright DIDI, Backhouse CM, Riddle E, McCollum CN. Sustained compression and healing of chronic venous ulcers. Br Med f 1988:297: $1159-61$.

19 Arenas R, Atoche C. Post-thrombotic leg ulcers: safety and efficacy of treat ment with pentoxifylline (double-blind study in 30 patients). Dermatologica. ment with pentoxifylline double-blind study in 30

20 Levh F. Therapic des Ulcus cruris venosum mit Mäusedornextrakt und Trimethylhesperidinchalkon. Therapiewoche 1988:38:2325-31.

21 Belcaro $\mathrm{G}$, Marelli $\mathrm{C}$. Treatment of venous lipodermatosclerosis and ulceration Belcaro $\mathrm{G}$, Marelli $\mathrm{C}$. Treatment of venous lipodermatosclerosis and ulceration
in venous hypertension by elastic compression and fibrinolytic enhancement in venous hypertension by elastic compression ar
with defibrotide. Phlebology 1989;4:91-106.

$22 \mathrm{Mann}$ RJ. A double blind trial of oral $\mathrm{O}, 6$-hydroxyethyl rutosides for statis leg ulcers. Br f Clin Pract 1981;35:79-8

23 Schraibman IG. The bacteriology of leg ulcers. Phlebology 1987;2:265-70.

24 Ward A, Clissold SP. Pentoxifylline: a review of its pharmacodynamic and pharmacokinetic properties, and its therapeutic efficacy. Drugs 1987;34 $50-97$

25 James DR, Holland BM, Hughes MR, Jones JG, Wardrop CAJ. Oxpentifvlline: effects on red cell deformability and oxvgen availability from the blood in intermittent claudication. Clinical Hemorrheologv 1984:4:525-31.

26 Angelkort B, Kiesewetter $\mathrm{H}$. Influence of risk factors and coagulation phenomena on the fluidity of blood in chronic arterial occlusive disease. Scand f Clin Lab Invest 1984;41/suppl 156):185-8.

27 Knox P Lelocyte-mediated activation of the fbrinolyeic parhway and the effects of ponction encen Pharmaceuticals, 1988:96-104.

28 Bertocchi F, Proserpio P, Lampugnani MG, Dejana E. The effect of pentoxifylline on polymorphonuclear cell adhesion to cultured endothelia cells. A preliminary report. In: Mandell GL, Novick WJ, eds. Pentoxifyllin and leukocyte function. Somerville, New Jersey: Hoechst-Roussel Pharmaceuticals, 1988:68-74.

Accepted 15 fanuary 1990

\title{
Relation between dose of bendrofluazide, antihypertensive effect, and adverse biochemical effects
}

\author{
Jan E Carlsen, Lars Køber, Christian Torp-Pedersen, Peter Johansen
}

Abstract

Objective-To determine the relevant dose of bendrofluazide for treating mild to moderate hypertension.

Design-Double blind parallel group trial of patients who were given placebo for six weeks and then randomly allocated to various doses of bendrofluazide $(1 \cdot 25,2 \cdot 5,5$, or $10 \mathrm{mg}$ daily) or placebo for 12 weeks.

Setting-General practices in Zealand, Denmark.

Patients - 257 Patients with newly diagnosed or previously treated hypertension, aged $25-70$, who had a mean diastolic blood pressure of $100-120 \mathrm{~mm}$ $\mathrm{Hg}$ after receiving placebo for six weeks.

Main outcome measures-Reduction in diastolic blood pressure and changes in biochemical variables (potassium, urate, glucose, fructosamine, total cholesterol, apolipoprotein A I, apolipoprotein B, and triglyceride concentrations).

Results - All doses of bendrofluazide significantly reduced diastolic blood pressure to the same degree $(10-11 \mathrm{~mm} \mathrm{Hg})$. Clear relations between dose and effect were shown for potassium, urate, glucose, total cholesterol, and apolipoprotein B concentrations. The $1.25 \mathrm{mg}$ dose increased only urate concentrations, whereas the $10 \mathrm{mg}$ dose affected all the above biochemical variables.

Conclusion-The relevant range of doses of bendrofluazide to treat mild to moderate hypertension is $\mathbf{1} \cdot \mathbf{2 5}-\mathbf{2} \cdot 5 \mathrm{mg}$ a day. Higher doses caused more pronounced adverse biochemical effects including adverse lipid effects. Previous trials with bendrofluazide have used too high doses.

Medicon, Svanemøllevej 2, DK-2100, København $\emptyset$, Denmark

Jan E Carlsen, MD, senior lecturer

Lars Køber, MD, resident Christian Torp-Pedersen, $\mathrm{MD}$, senior lecturer

Leo Pharmaceutical Products, Industriparken, DK-2750, Ballerup, Denmark

Peter Johansen, PHD, medical adviser

Correspondence to:

Dr Carlsen.

$\operatorname{Br} \operatorname{Med} \mathcal{f} 1990 ; 300: 975-8$ fluazide $(10 \mathrm{mg} /$ day $)$ or a titrated dose of propranolo with placebo. ' 2 There was no basis for choosing a dose of $10 \mathrm{mg}$ bendrofluazide.

We investigated the relevant dose range of bendro- fluazide for treating mild to moderate arterial hypertension as this could affect both the choice and outcome of treatment.

\section{Methods}

Selection of patients--Patients aged 25-70 presenting to general practices in Zealand, Denmark, with newly diagnosed or previously treated arterial hypertension (up to two drugs) who gave informed consent were eligible for the study.

Patients were excluded if they were pregnant or lactating; had had a myocardial infarction or stroke within the past six months; had angina pectoris; were being treated for heart failure, gout, or uncontrolled diabetes mellitus or with drugs that reduced lipid concentrations; were intolerant of bendrofluazide; had reduced kidney function (creatinine concentration $>150 \mu \mathrm{mol} / \mathrm{l}$ ); did not take $80-120 \%$ of the prescribed tablets while receiving a placebo at the start of the study.

Study design-Patients whose blood pressure was between 100 and $120 \mathrm{~mm} \mathrm{Hg}$ after they had taken placebo for six weeks were randomly allocated in blocks of 10 on a double blind basis to receive placebo or bendrofluazide at a dose of $1 \cdot 25,2 \cdot 5,5$, or 10 mg a day. Randomisation was performed from a list of computer generated numbers. The $10 \mathrm{mg}$ dose was chosen because this was used in the Medical Research Council's trial and the 2.5 and $5 \mathrm{mg}$ doses because they are recommended by the joint national committee on detection, evaluation, and treatment of high blood pressure. ${ }^{3}$ The dose of $1.25 \mathrm{mg}$ was believed to represent a point on the lower part of the dose-response curve. The active tablets contained $573 \mathrm{mg}$ potassium chloride and either $1.25 \mathrm{mg}$ or $2.5 \mathrm{mg}$ bendrofluazide (Centyl K, Leo Pharmaceutical Products). Placebo and active tablets were identical in appearance and taste. All patients received four tablets daily, two in the morning and two at lunch. Those receiving fewer than four active tablets daily were given the active tablets in the morning. Patients were assessed on an outpatient basis for four, 10, and 12 weeks after randomisation. Biochemical variables were measured before randomisation and at the end of the study; these variables included total cholesterol, apolipoprotein A I, apolipoprotein B, sodium, potassium, glucose, fructosamine, urate, and creatinine concentrations. The study was approved by the local ethical committee.

Methods of assessment-The patient's blood pressures were measured twice, in the sitting position after five 
minutes' rest, with a random zero sphygmomanometer (Hawksley) and a Tricuff. Diastolic blood pressure was taken at the point where Korotkoff sounds disappeared (phase V). Three trained nurses took all the blood pressure measurements. Heart rate was assessed by counting the radial pulse. At each visit patients were asked about adverse effects. All biochemical analyses were carried out in a high quality automated laboratory (CALAB, Stockholm, Sweden).

Statistical analyses-All values are given as means

TABLE I-Demographic characteristics of 257 patients with mild to moderate hypertension

\begin{tabular}{lccccc}
\hline & \multicolumn{5}{c}{ Dose of bendrofluazide $(\mathrm{mg} /$ day $)$} \\
\cline { 2 - 6 } & 0 & $1 \cdot 25$ & $2 \cdot 5$ & $5 \cdot 0$ & $10 \cdot 0$ \\
\hline No & 52 & 50 & 52 & 52 & 51 \\
No of men & 23 & 16 & 17 & 19 & 28 \\
Mean age (years) & 57 & 60 & 54 & 57 & 59 \\
Mean weight $(\mathrm{kg})$ & 75 & 75 & 73 & 79 & 72 \\
\hline
\end{tabular}

TABLE II - Variation in blood pressure and heart rate in 257 patients throughout trial according to amount of drug taken. All values are means (SE)

\begin{tabular}{|c|c|c|c|c|c|}
\hline & \multicolumn{5}{|c|}{ Dose of bendrofluazide (mg/day) } \\
\hline & $\begin{array}{c}0 \\
(\mathbf{n}=52)\end{array}$ & $\begin{array}{c}1 \cdot 25 \\
(\mathrm{n}=50)\end{array}$ & $\begin{array}{c}2 \cdot 5 \\
(\mathrm{n}=52)\end{array}$ & $\begin{array}{c}5 \cdot 0 \\
(n=52)\end{array}$ & $\begin{array}{c}10 \cdot 0 \\
(n=51)\end{array}$ \\
\hline \multicolumn{6}{|c|}{ Value at start of trial } \\
\hline Systolic blood pressure $(\mathrm{mm} \mathrm{Hg})$ & $161.9(1.9)$ & $167 \cdot 8(2 \cdot 6)$ & $161 \cdot 6(1 \cdot 9)$ & $164 \cdot 3(1 \cdot 8)$ & $166 \cdot 9(2 \cdot 7)$ \\
\hline Diastolic blood pressure $(\mathrm{mm} \mathrm{Hg})$ & $101 \cdot 8(0 \cdot 5)$ & $102 \cdot 4(0 \cdot 6)$ & $103 \cdot 0(0 \cdot 6)$ & $104 \cdot 2(0 \cdot 9)$ & $103 \cdot 7(0 \cdot 8)$ \\
\hline Heart rate (beats $/ \mathrm{min}$ ) & $74 \cdot 8(1 \cdot 0)$ & $75 \cdot 8(1 \cdot 2)$ & $75 \cdot 8(1 \cdot 5)$ & $77 \cdot 5(1 \cdot 0)$ & $75 \cdot 4(1 \cdot 0)$ \\
\hline \multicolumn{6}{|c|}{ Difference at week 4} \\
\hline Systolic blood pressure $(\mathrm{mm} \mathrm{Hg})$ & $-0 \cdot 9(1 \cdot 8)$ & $-6 \cdot 4(2 \cdot 0)$ & $-11 \cdot 3(2 \cdot 1)$ & $-11 \cdot 5(1 \cdot 8)$ & $-11 \cdot 7(1 \cdot 8)$ \\
\hline Diastolic blood pressure $(\mathrm{mm} \mathrm{Hg})$ & $-2 \cdot 9(0 \cdot 9)$ & $-7 \cdot 5(1 \cdot 1)$ & $-8 \cdot 7(0 \cdot 8)$ & $-8 \cdot 1(1 \cdot 1)$ & $-9 \cdot 0(1 \cdot 0)$ \\
\hline Heart rate (beats/min) & $-1 \cdot 9(1 \cdot 0)$ & $-2 \cdot 4(1 \cdot 1)$ & $-1 \cdot 8(1 \cdot 5)$ & $-0 \cdot 1(1 \cdot 3)$ & $-0.5(1.4)$ \\
\hline \multicolumn{6}{|c|}{ Difference at mean of 10-12 weeks' treatment } \\
\hline Systolic blood pressure $(\mathrm{mm} \mathrm{Hg})$ & $-2 \cdot 8(1 \cdot 7)$ & $-12 \cdot 7(2 \cdot 0)^{\star \star}$ & $-14 \cdot 3(1 \cdot 6)$ & $-13 \cdot 4(2 \cdot 0)$ & $-17 \cdot 0(2 \cdot 1)^{\star \star}$ \\
\hline Diastolic blood pressure $(\mathrm{mm} \mathrm{Hg})$ & $-3 \cdot 5(0 \cdot 8)$ & $-9 \cdot 8(1 \cdot 0)^{\star}$ & $-10 \cdot 8(0 \cdot 9)^{\star}$ & $-10 \cdot 1(1 \cdot 1)$ & $-10 \cdot 8(1 \cdot 0)$ \\
\hline Heart rate (beats/min) & $-0 \cdot 7(1 \cdot 1)$ & $-1 \cdot 2(1 \cdot 0)$ & $-0 \cdot 6(1 \cdot 3)$ & $0.8(1 \cdot 1)$ & $-2 \cdot 5(1 \cdot 1)$ \\
\hline
\end{tabular}

$\star=\mathrm{p}<0 \cdot 05,{ }^{\star}=\mathrm{p}<0 \cdot 01$, comparing weeks $10-12$ with week 4 . and standard errors (SE). Discrete variables were compared with a $\gamma^{2}$ test and continuous variables, which were checked for normal distribution and equal variance, with Student's $t$ test. Significance was accepted if type I error risk was below 5\% (two sided).

Sample size - The sample size was calculated according to the methods of Dunnett. ${ }^{+}$We planned to have equal numbers in each group. The minimal relevant difference was considered to be $5 \mathrm{~mm} \mathrm{Hg}$ and the standard deviation estimated to $7 \mathrm{~mm} \mathrm{Hg}$. With type I and type II error risks of $5 \%$ and $10 \%$ we needed 50 patients in each group.

\section{Results}

Table I shows the demographic data on the patients. There were no large differences among the groups.

Table II shows the changes in blood pressures during the study. The diastolic blood pressure decreased significantly in all groups: by $3 \mathrm{~mm} \mathrm{Hg}$ in the placebo group and $10-11 \mathrm{~mm} \mathrm{Hg}$ in the actively treated groups. The dose of bendrofluazide did not significantly affect the reduction in diastolic blood pressure. The mean difference in diastolic pressure between the $1.25 \mathrm{mg}$ and $2.5 \mathrm{mg}$ doses was $-1.2 \mathrm{~mm} \mathrm{Hg}(95 \%$ confidence interval -3.9 to 1.5$)$ at week 4 and $-1.0 \mathrm{~mm} \mathrm{Hg}(95 \%$ confidence interval -3.7 to 1.7 ) at the end of the trial.

The systolic blood pressure in the placebo group did not change, although in the treated groups it decreased by $13-17 \mathrm{~mm} \mathrm{Hg}$ with no significant difference between groups. The mean difference in systolic pressure between the $1.25 \mathrm{mg}$ and $2.5 \mathrm{mg}$ doses was $-4.9 \mathrm{~mm}$ $\mathrm{Hg}(95 \%$ confidence interval -10.6 to 0.8$)$ at week 4 and $-1.6 \mathrm{~mm} \mathrm{Hg}(95 \%$ confidence interval -6.6 to $3.4)$ at the end of the trial. Changes in blood pressure occurred slowly. Only a partial effect was present for both the systolic and diastolic pressures after four weeks' treatment. The heart rate did not change in any group.

TABLE III - Number (percentage; 95\% confidence interval) of patients whose diastolic blood pressure dropped by $\geqslant 10 \mathrm{~mm} \mathrm{Hg} \mathrm{during} \mathrm{trial}$

\begin{tabular}{lccccc}
\hline & & & Dose of bendrofluazide (mg/day $)$ & \\
\cline { 2 - 6 } & 0 & $1 \cdot 25$ & $2 \cdot 5$ & $5 \cdot 0$ & $10 \cdot 0$ \\
\hline Week 4 $10-12$ weeks' treatment & $6(12 ; 4$ to 23$)$ & $19(38 ; 24$ to 51$)$ & $21(40 ; 27$ to 55$)$ & $21(40 ; 27$ to 55$)$ & $22(43 ; 30$ to 58$)$ \\
Mean of $10 ;$ to 23$)$ & $22(44 ; 29$ to 57$)$ & $25(48 ; 34$ to 62$)$ & $26(50 ; 36$ to 64$)$ & $27(53 ; 39$ to 67$)$
\end{tabular}

TABLE IV-Mean (SE) values of biochemical variables at beginning of trial and change after 10 weeks' treatment

\begin{tabular}{|c|c|c|c|c|c|c|c|c|c|c|c|}
\hline \multirow[b]{3}{*}{ Potassium $(\mathrm{mmol} / \mathrm{l}):$} & \multicolumn{10}{|c|}{ Dose of bendrofluazide (mg/day) } & \multirow[b]{2}{*}{$\mathrm{p}$ Value } \\
\hline & \multicolumn{2}{|r|}{$0 \cdot 0$} & \multicolumn{2}{|r|}{$1 \cdot 25$} & \multicolumn{2}{|r|}{$2 \cdot 5$} & \multicolumn{2}{|r|}{$5 \cdot 0$} & \multicolumn{2}{|c|}{$10 \cdot 0$} & \\
\hline & & & & & & & & & & & \\
\hline Baseline & $4 \cdot 36$ & $6(0.05)$ & $4 \cdot 27$ & $7(0.06)$ & $4 \cdot 25$ & $(0.05)$ & $4 \cdot 32$ & $(0.06)$ & $4 \cdot 33$ & $(0.05)$ & \\
\hline Change at 10 weeks & 0.09 & $9(0.06)$ & -0.16 & $6(0.06)$ & $-0 \cdot 20$ & $(0.05)^{\star}$ & -0.33 & $3(0.06)^{\star \star \star \star}$ & -0.45 & $(0.06)^{\star \star \star \star}$ & \\
\hline \multicolumn{12}{|l|}{ Urate $(\mu \mathrm{mol} / \mathrm{l})$ : } \\
\hline Baseline & $300 \cdot 0$ & $(11 \cdot 0)$ & $314 \cdot 0$ & $(11 \cdot 2)$ & $324 \cdot 0$ & $(10 \cdot 7)$ & $324 \cdot 0$ & $(11 \cdot 3)$ & $322 \cdot 0$ & $9 \cdot 7$ & \\
\hline Change at 10 weeks & $-5 \cdot 0$ & $(5 \cdot 3)$ & $19 \cdot 0$ & $(6 \cdot 1)^{\star \star}$ & $29 \cdot 0$ & $(7 \cdot 7)^{\star \star \star \star}$ & 63.0 & $(14 \cdot 3)^{\star \star \star}$ & $68 \cdot 0$ & $(7 \cdot 5) \star \star \star$ & \\
\hline \multicolumn{12}{|l|}{ Creatinine $(\mu \mathrm{mol} / \mathrm{l})$ : } \\
\hline Baseline & $85 \cdot 0$ & $(2 \cdot 4)$ & $78 \cdot 6$ & $(1.9)$ & 81.5 & $(1 \cdot 8)$ & $79 \cdot 0$ & $(2 \cdot 4)$ & $86 \cdot 4$ & $(3 \cdot 2)$ & \\
\hline Change at 10 weeks & -2.7 & $(1.6)$ & $2 \cdot 4$ & $(1 \cdot 6)^{\star}$ & 2.5 & $(1 \cdot 4)^{\star}$ & $2 \cdot 3$ & $(3 \cdot 0)$ & 3.8 & $(1.4)^{\star \star \star}$ & 0.068 \\
\hline \multicolumn{12}{|l|}{ Glucose $(\mu \mathrm{mol} / 1):$} \\
\hline Baseline & $4 \cdot 88$ & $8(0 \cdot 10)$ & $5 \cdot 31$ & $(0 \cdot 19)$ & $4 \cdot 77$ & $(0 \cdot 12)$ & $5 \cdot 10$ & $(0 \cdot 10)$ & 4.96 & $(0 \cdot 11)$ & \\
\hline Change at 10 weeks & -0.08 & $8(0.09)$ & -0.19 & $9(0.11)$ & 0.14 & $(0 \cdot 10)$ & 0.04 & $(0 \cdot 10)$ & 0.27 & $(0.15)^{\star}$ & 0.008 \\
\hline \multicolumn{12}{|l|}{ Fructosamine $(\mathrm{mmol} / \mathrm{l})$ : } \\
\hline $\begin{array}{l}\text { Baseline } \\
\text { B }\end{array}$ & 2.08 & $3(0.03)$ & $2 \cdot 12$ & $2(0.04)$ & 2.08 & $(0.03)$ & 2.07 & $(0.03)$ & 2.06 & $(0.03)$ & \\
\hline Change at 10 weeks & -0.02 & $2(0.03)$ & -0.01 & $1(0.04)$ & 0.03 & $(0.03$ & 0.03 & 30.03 & 0.06 & $0.04)$ & 0.066 \\
\hline \multicolumn{12}{|l|}{ Cholesterol $(\mathrm{mmol} / \mathrm{l})$ : } \\
\hline Baseline & 5.99 & $9(0.15)$ & 6.53 & $(0.15)$ & $5 \cdot 86$ & $(0 \cdot 16)$ & $6 \cdot 03$ & $3(0.13)$ & $5 \cdot 84$ & $(0 \cdot 17)$ & \\
\hline Change at 10 weeks & -0.06 & $6(0.09)$ & -0.03 & $3(0.11)$ & 0.00 & 0.09 & $0 \cdot 12$ & $2(0 \cdot 10)$ & 0.25 & $(0.09)^{\star}$ & 0.01 \\
\hline \multicolumn{12}{|l|}{ Apolipoprotein A I $(\mathrm{g} / 1)$ : } \\
\hline Baseline & $1 \cdot 38$ & $3(0.02)$ & $1 \cdot 36$ & $5(0.02)$ & 1.34 & $(0.03)$ & 1.39 & $(0.03)$ & $1 \cdot 30$ & $(0.03)$ & \\
\hline Change at 10 weeks & 0.01 & $(0.02)$ & 0.02 & $2(0.02)$ & 0.02 & $(0.02)$ & 0.02 & $2(0.02)$ & 0.01 & $(0.02)$ & 0.999 \\
\hline \multicolumn{12}{|l|}{ Apolipoprotein $\mathrm{B}(\mathrm{g} / \mathrm{l})$ : } \\
\hline Baseline & $1 \cdot 23$ & $3(0.03)$ & 1.39 & $9(0.04)$ & $1 \cdot 26$ & $(0.04)$ & $1 \cdot 21$ & $(0.03)$ & $1 \cdot 23$ & $(0.04)$ & \\
\hline Change at 10 weeks & 0.02 & $2(0.02)$ & -0.01 & $1(0.03)$ & -0.07 & $(0.03)^{\star}$ & 0.04 & $+0.03)$ & 0.07 & $(0.03)$ & 0.02 \\
\hline \multicolumn{12}{|l|}{ Trigluceride $(\mathrm{mmol} / \mathrm{l})$ : } \\
\hline Baseline & $1 \cdot 48$ & $3(0.17)$ & 1.62 & $2(0 \cdot 12)$ & 1.55 & $(0 \cdot 18)$ & 1.93 & $3(0.23)$ & $1 \cdot 38$ & $(0 \cdot 11)$ & \\
\hline Change at 10 weeks & -0.13 & $3(0.15)$ & 0.00 & $5(0 \cdot 10)$ & 0.39 & $(0.12)^{\star}$ & -0.05 & $5(0.22)$ & $0 \cdot 14$ & $(0.09)$ & 0.53 \\
\hline
\end{tabular}

${ }^{\star} \mathrm{p}<0.05,{ }^{\star \star} \mathrm{p}<0.01,{ }^{\star \star \star} \mathrm{p}<0.001$ compared with placebo.

$p$ Value denotes significance between the change and the dose of bendrofluazide. 
We defined responders as patients whose diastolic blood pressure decreased by $\geqslant 10 \mathrm{~mm} \mathrm{Hg}$ (table III). The number of responders increased from week 4 to the end of the trial in all groups receiving bendrofluazide. Roughly half of the actively treated patients were responders

Table IV shows the baseline biochemical values and the changes that occurred during the study. No correlation existed beween the dose of bendrofluazide and the change in apolipoprotein A I and triglyceride concentrations. Marginal correlations were found with creatinine and fructosamine concentrations, and highly significant correlations with glucose, total cholesterol, potassium, apolipoprotein $B$, and urate concentrations. The lowest doses of bendrofluazide $(1.25 \mathrm{mg}$ and 2.5 $\mathrm{mg}$ ) significantly increased creatinine and urate concentrations, and the $2.5 \mathrm{mg}$ dose also decreased potassium concentrations. Changes induced by the two highest doses were more pronounced: the $10 \mathrm{mg}$ dose significantly changed potassium, urate, creatinine, glucose, and total cholesterol concentrations.

Nine patients were withdrawn from the study because of subjective adverse effects: one from the group receiving $5 \mathrm{mg} /$ day and two in each of the other groups. Forty seven patients experienced adverse effects (table V), and in 21 of them the effects were typical of thiazides. We found no relation between either biochemical changes or subjective adverse effects and changes in blood pressure. The response to treatment was not affected by gender.

TABLE V-Adverse effects experienced by patients participating in trial of bendrofluazide

\begin{tabular}{|c|c|c|c|c|c|}
\hline & \multicolumn{5}{|c|}{ Dose of bendrofluazide (mg/day) } \\
\hline & 0 & $1 \cdot 25$ & $2 \cdot 5$ & $5 \cdot 0$ & $10 \cdot 0$ \\
\hline Attack of gout & & & 1 & & \\
\hline Impotence & & & 1 & & 1 \\
\hline Constipation & & & & & 4 \\
\hline Leg pain & & & 1 & & 3 \\
\hline Headache & 4 & 1 & $i$ & & \\
\hline Dry mouth & & & 2 & 1 & 3 \\
\hline Dizziness & & 1 & 3 & 1 & 4 \\
\hline Frequent voiding of bladder & & & & & 3 \\
\hline Palpitations & & & & 3 & \\
\hline Others & 5 & 6 & 5 & 7 & 6 \\
\hline Total & 9 & 8 & 14 & 12 & 24 \\
\hline
\end{tabular}

\section{Discussion}

Drug trials should not be conducted without knowing the relevant dose. ${ }^{5}$ Hypertension is treated to prevent mortality and morbidity, and an ideal doseresponse study should establish the relation between the dose and the reduction in mortality and morbidity. Obviously, such studies are not feasible so the relation between the dose and the antihypertensive effect is usually studied. The dose that lowers the blood pressure most does not necessarily have the greatest effect on mortality and morbidity.

When deciding on the dose for clinical use it is necessary to strike a balance between unwanted and wanted effects. Several antihypertensive drugs have been introduced with too high doses. Both the number and the severity of adverse effects can be reduced by using smaller doses without affecting the efficacy. Thiazides are used to treat several conditions, and the optimal dose for each condition is not the same, as was assumed in early studies. ${ }^{6}$

Knowledge of the time course of wanted and unwanted effects with all doses is important. Constructing dose-response curves before the full effect is obtained shifts the curve to the right and reduces the apparent efficacy. We measured blood pressures after three months of treatment, when both blood pressure and biochemical effects should have stabilised. . $^{8-10}$ If measurements had been taken earlier the antihypertensive effect of the $1.25 \mathrm{mg}$ dose would not have been seen as it occurred slowly. The method of expressing the effect of antihypertensive drugs (in absolute figures, as a percentage reduction in blood pressure, or by number of responders) did not affect the conclusion.

Hypertensive patients who do not respond to thiazides are characterised by activation of the reninangiotensin system and increased aldosterone concentrations. ${ }^{11}$ Thus biochemical effects may differ between responders and non-responders. We found no such differences.

Increasing the dose of bendrofluazide increases the adverse biochemical effects but not hypertensive activity. Thiazides have been criticised mainly for their biochemical effects, ${ }^{12}{ }^{13}$ but bendrofluazide at a dose of $1.25 \mathrm{mg}$ caused only one relevant effect (a $6 \%$ increase in urate concentration). Thus much of the criticism of thiazides is based on use of too high doses.

Hypokalaemia induced by thiazides seems not to cause arrhythmias as was previously thought, ${ }^{1+15}$ but limiting hypokalaemia must be beneficial. A substudy of the Medical Research Council's trial found no benefit in potassium supplementation. ${ }^{16}$ Thus giving potassium with the bendrofluazide may not have been important. We found that the decrease in potassium concentration was mainly related to the dose of thiazide.

Thiazides are known to impair glucose tolerance. ${ }^{17}$ We found a clear correlation between the dose and an increase in fasting glucose concentrations, but only the $10 \mathrm{mg}$ dose gave a significant effect. Recently the same effect was reported for hydrochlorothiazide at an average dose of $40 \mathrm{mg}$ a day. ${ }^{18}$

Recently, interest has focused on adverse effects of hypertensive drugs on lipid profiles. ${ }^{1920}$ Numerous studies have shown that diuretics adversely alter lipoprotein metabolism at least during short term trials, but this was found with high doses compared with the dose suggested by this study. It is unknown whether the effect on lipoprotein metabolism is related to dose. ${ }^{1920}$ We showed clear relations between the dose of bendrofluazide and both total cholesterol and apolipoprotein $B$ concentrations, which were consistent with the results of other studies. ${ }^{18-20}$ We therefore conclude that the adverse effect of diuretics on lipoprotein metabolism is related to dose and could be avoided by prescribing lower doses. When evaluating comparative trials between thiazides and newer treatments it is important to be aware of the drug doses. A recent report claimed that captopril has less effect on glucose and lipoprotein metabolism than hydrochlorothiazide. ${ }^{18}$ The dose of hydrochlorothiazide was on average 40 (SD 12) $\mathrm{mg}$, and thus more than $60 \%$ of the patients received an unrealistically high dose, creating a bias in favour of captopril.

Thiazides have been suggested to increase mortality and morbidity from acute myocardial infarction due to their effects on lipids. ${ }^{21}$ Re-evaluation of the data does not confirm this, and several trials have found that thiazides do not alter mortality and morbidity. ${ }^{2223}$ The antihypertensive effect of thiazides may decrease the risk of acute myocardial infarction, but this is counteracted by increases in total and low density lipoprotein cholesterol concentrations. If the adverse lipid profile is considered important our findings suggest that new mortality studies using correct doses of thiazide should be performed.

The Medical Research Council's trial found an unexpectedly high number of subjective adverse effects. ${ }^{1}$ Our study, although indicating that increasing the dose increases the number of adverse effects, was too small to be conclusive on this problem. A Medical Research Council substudy, which compared 5 and 10 
$\mathrm{mg}$ bendrofluazide daily, found fewer adverse effects in the low dose group, ${ }^{16}$ as did a long term trial of the 5 in the group given $1.25 \mathrm{mg}$ was the same as that in the group given placebo, although the effects were different. Patients' symptoms are known to change when they receive antihypertensive treatment. We conclude that in low doses thiazides are one of the most effective and well tolerated treatments for arterial hypertension.

1 Medical Research Council W'urking Party on Mild to Moderate Hypertension. Adverse reactions of hendrofluazide and propranolol for the treatment of mild hypertension. Lancet 1981;ii:539-43.

2 Medical Research Council Working Party. MRC trial of treatment of mild hypertension: principal results. Br.Med f 1985:291:97-104.

31988 Joint National Committee. The 1988 report of the joint national committee on detection, evaluation, and treatment of high blood pressure. Arch Inter Med 1988;148:1023-38

+ Dunnett CW. Selection of the best treatment in comparison to a control with an application to a medical trial. In: Santner TJ, Tamhane AC, eds. Design of experiments. Statistics: textbooks and monographs. Ranking and selection. Vo 56. New York: Marcel Dekker, 1984: 47-66.

5 Gotzsche PC, Hvidberg EF, Juul P. Rational choice of dose: insufficient background knowledge? Ration Drug Ther 1986;20:1-7.

6 Ford RV, Nickell J. Experimental and laboratory reports: pharmacologic observations on a more potent benzothiadiazine diuretic (Be. 724-A). observations on a more por
Am Heart $f$ 1960;59:215-23.

7 Cranston W'I, Juel-Jensen BE, Semmence AM, Jones RPCH, Forbes JA, Mutch LMM. Effects of oral diuretics on raised arterial pressure. Lancel 1963;ii:966-70.

8 Berglund $\mathrm{G}$, Andersson $\mathrm{O}$, Larsson $\mathrm{O}$, Wilhelmsen L. Antihypertensive effect 1976;199:499-506

9 Papademetriou V, Price M, Johnson E, Smith M, Freis ED. Early changes in plasma and urine potassium in diuretic-treated patients with systemic hypertension. Am F Cardiol 1984:54:1015-9. mg dose. ${ }^{8}$ We found that the number of adverse effects and side-effects of bendroflumethiazide and propranolol. Acta Med Scand

10 Wilkinson PR, Hesp R, Issler H, Raftery EB. Total hody and serum potassium during prolonged thiazide therapy for essential hypertension. Lance $1975 ;$; $7599-62$.

11 Weber MA, Drayer JIM. Single-agent and combination therapy of essential hypertension. Am Heart f 1984; 108:311-6.

12 McCarron DA. Diuretic therapy for mild hypertension: the "real" cost of treatment. Am f Cardiol 1984;53:9-11A.

13 Leren P, Foss OP, Helgeland A, Hjermann I, Holme I. Effects of pindolol and hydrochlorothiazide on blood lipids-the Oslo study. Clinical Trials fournal 1981;18:254-61.

14 Medical Research Council Working Party on Mild to Moderate Hypertension. Ventricular extrasustoles during thiazide treatment: substudy of $M R C$ mild hypertension trial. Br.Med f 1983;287:1249-53.

15 Papademetriou V, Burris JF, Notargiacomo A, Fletcher RD, Freis ED Thiazide therapy is not a cause of arrhythmia in patients with systemi hypertension. Arch Intern Med 1988;148:1272-6.

16 Medical Research Council Working Party. Comparison of the antihypertensive efficacy and adverse reactions to two doses of bendrofluazide and hydrochlorothiazide and the effect of potassium supplementation on the hypotensive action of bendrofluazide: substudies of the Medical Research Council's trials of treatment of mild hypertension. $\mathcal{f}$ Clin Pharmacol 1987;27:271-7.

17 Veterans Administration Cooperative Study Group on Antihypertensive Agents. Propranolol or hydrochlorothiazide alone for the initial treatment of hypertension. Hypertension 1985; 7:1008-16.

18 Pollare T, Lithell $\mathrm{H}$, Berne C. A comparison of the effect of hydrochlorothiazide and captopril on glucose and lipid metabolism in patients with hypertension. $N$ Engl f Med 1989;321:868-73.

19 Ames RP. Antihypertensive drugs and lipid profiles. Am 7 Hyperten $1988 ; 1: 421-7$.

20 Lardinois CK, Neuman SL. The effects of antihypertensive agents on serum lipids and lipoproteins. Arch Intern Med 1988;148:1280-8.

21 Multiple Risk Factor Intervention Trial. Risk factor changes and mortality results. FAMA 1982;248:1465-7.

22 Management Committee. The Australian therapeutic trial in mild hypertension. Lancet 1980; i:1261-7.

23 Wilhelmsen L, Berglund G, Elmfeldt D, et al. Beta-blockers versus diuretics in hypertensive men: main results from the HAPPHY trial. $\mathcal{f}$ Hyperten 1987;5:561-72.

(Accepted 7 February 1990

Possible predisposing factors in 317 patients presenting to an emergency department after a seizure

\begin{tabular}{lccc}
\hline & $\begin{array}{c}\text { First seizure } \\
(\mathbf{n}=155)\end{array}$ & $\begin{array}{c}\text { Recurrent seizure } \\
(\mathbf{n}=162)\end{array}$ & $\begin{array}{c}\text { Total (\%) } \\
(\mathbf{n}=317)\end{array}$ \\
\hline Alcohol abuse & 96 & 97 & $193(60)$ \\
Head injury & 17 & 31 & $48(15)$ \\
Vascular accident & 13 & 9 & $22(7)$ \\
Neoplasm & 8 & 5 & $13(4)$ \\
Infection & 1 & 9 & $10(3)$ \\
Atrophy & 8 & 2 & $10(3)$ \\
Drug related & 7 & 2 & $9(3)$ \\
Metabolic abnormality & 5 & 3 & $8(3)$ \\
Arteriovenous malformation & 0 & 4 & $4(2)$ \\
\hline
\end{tabular}
time. ${ }^{2}$ Anyone experiencing a first fit is likely to be referred as an emergency. There have been studies in the United States of how such patients are managed, ${ }^{3}$ but none have been reported from the United Kingdom. We report on the management of patients who presented over two years at a casualty department after a seizure.

\section{Patients, methods, and results}

We obtained the names of patients recorded as having had a "seizure" or a "blackout" in 1985 and 1986 from the casualty register of this hospital, a 600 bed teaching hospital serving a population of 325000 . One or more of the following criteria were required: $(a)$ description by an independent witness; (b) appropriate history with postictal clinical signs; (c) a further witnessed seizure in the casualty department; $(d)$ loss of consciousness in a patient known to have epilepsy. We obtained the hospital case sheet for each patient and completed a standard form from the data available during the year after the initial presentation.

From a total of 50000 referrals in 1985 and 1986 we identified seizures in 597 patients (370 (62\%) men, 227 (38\%) women; mean age 41 years, range 12-88 years). Of these, $260(44 \%)$ patients (mean age 44) had had their first fit. The other 337 patients (mean age 38) were known to have epilepsy, and the presenting event was regarded as a "recurrent" seizure.

Of the seizures, $498(83.5 \%)$ were generalised tonicclonic fits. Sixty seven $(11 \cdot 3 \%)$ of the patients pre-

sented with a complex partial seizure, and $15(2 \cdot 5 \%)$ had multiple episodes. Only 11 patients were admitted in status epilepticus. One reported a simple partial seizure, and a further four fits remained unclassified. The table lists possible predisposing factors in 317 (53\%) patients

After referral $331(55 \%)$ patients were being treated with one or more anticonvulsant drugs $(20 \%$ who had a first seizure, $80 \%$ who had recurrent seizures). Of these, $251(76 \%)$ took one drug (carbamazepine 93 , phenytoin 83 , sodium valproate 45 , phenobarbitone 23 , primidone 7$), 70(21 \%)$ took two drugs, and $10(3 \%)$ took three drugs. More patients with an "abnormal" electroencephalogram received anticonvulsant drugs $(\mathrm{n}=303,62 \%$ abnormal $v 39 \%$ normal, $\chi^{2}$ test: $\left.p<0 \cdot 005\right)$. This was not the case with positive results of computed tomography $(n=106,62 \%$ abnormal $v 60 \%$ normal)

Of the 260 patients with a first seizure, $46(18 \%)$ were discharged immediately and 28 given a follow up appointment. The other 214 patients were admitted to hospital: 137 (64\%) spent under 48 hours in a short stay facility, and $46(18 \%)$ were investigated in a general medical ward. Overall, of the 597 patients 371 (62\%) (167 with a first seizure; 204 with recurrent seizures) subsequently attended an outpatient clinic. Most (208; $56 \%)$ were seen by a general physician $(127(76 \%)$ first seizure, $79(39 \%)$ recurrent seizure); $93(36 \%)$ patients with a first seizure and $133(40 \%)$ with recurrent seizures did not attend for follow up. 